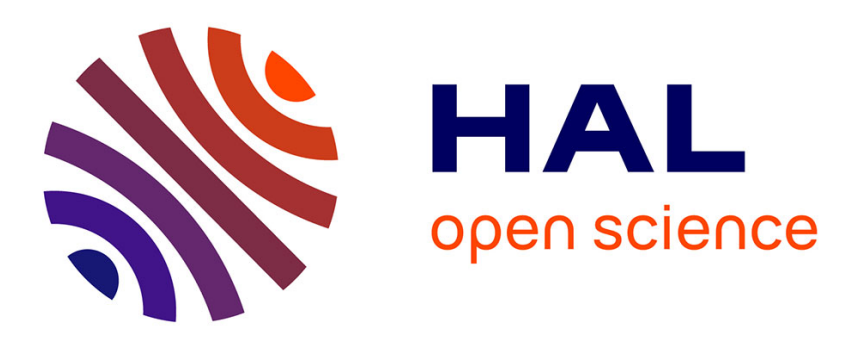

\title{
Understanding the Value of Using Smartphones for Older Adults in China: A Value-Focused Thinking Approach
}

Shang Gao, Ying Li, Hong Guo

\section{- To cite this version:}

Shang Gao, Ying Li, Hong Guo. Understanding the Value of Using Smartphones for Older Adults in China: A Value-Focused Thinking Approach. 18th Conference on e-Business, e-Services and e-Society (I3E), Sep 2019, Trondheim, Norway. pp.533-544, 10.1007/978-3-030-29374-1_43 . hal-02510138

\section{HAL Id: hal-02510138 \\ https://hal.inria.fr/hal-02510138}

Submitted on 17 Mar 2020

HAL is a multi-disciplinary open access archive for the deposit and dissemination of scientific research documents, whether they are published or not. The documents may come from teaching and research institutions in France or abroad, or from public or private research centers.
L'archive ouverte pluridisciplinaire HAL, est destinée au dépôt et à la diffusion de documents scientifiques de niveau recherche, publiés ou non, émanant des établissements d'enseignement et de recherche français ou étrangers, des laboratoires publics ou privés.

\section{(c)(1)}

Distributed under a Creative Commons Attribution| 4.0 International License 


\title{
Understanding the Value of Using Smartphones for Older Adults in China: A Value-Focused Thinking Approach
}

\author{
Shang Gao ${ }^{10000-0002-3722-6797]}$, Ying $\mathrm{Li}^{2}$, and Hong Guo ${ }^{3}$ \\ ${ }^{1}$ School of Business, Örebro University, Örebro, Sweden \\ ${ }^{2}$ School of Business Administration, Zhongnan University of Economics and Law, Wuhan, \\ China \\ ${ }^{3}$ Department of Computer Science, Norwegian University of Science and Technology, Trond- \\ heim, Norway \\ shang.gao@oru.se, liying0912@qq.com, homekuo@gmail.com
}

\begin{abstract}
This study aims to explore the values of using smartphones in older adults' daily lives in China. The value of using smartphones can be seen as the benefits associated with the use of smartphones in peoples' daily activities. By employing the Value-Focused Thinking (VFT) approach, this study investigates what fundamental objectives and means objectives are important with the daily use of smartphones for older adults in China. Based on the data collected from the interviews, we developed a means-ends objective network describing the values of using smartphones for older adults in China. According to the results, maximizing well-being, maximizing life efficiency, maximizing safety, and maximizing digital inclusion are identified as the fundamental objectives to maximize values of using smartphones for older adults in China.
\end{abstract}

Keywords: using smartphones, older adults, the Value-Focused Thinking (VFT) approach, means-ends objective network, value

\section{$1 \quad$ Introduction}

Today, smartphones have become an inseparable part of peoples' daily lives. A smart phone is a mobile phone with more advanced computing capability and connectivity than basic feature phones (e.g., calling, texting). It allows users to make mobile shopping, make mobile payments, watch videos, and so on. Smartphones have the potential to enhance the quality of peoples' lives $[8,9]$. For instance, smartphones come with social network functionality built in, which enable users to keep in touch with their friends and relatives on different social media sites (e.g., Twitter, Facebook, Wechat [7], and Instagram). Moreover, smartphones also come with music and video players built in, which enable users to listen to their favorite music, and watch video clips and TV shows. In [22], the authors found that using smartphones could enhance older adults' ability in different physical, mental, and social dimensions of life through enhancing their knowledge, facilitating their communication with friends, enabling their participation in social networks, and so on. 
Most countries in the world are experiencing an increase in terms of the medium age of population. The ageing of the population is one of the major challenges most countries have to face over the next few decades [23]. Although the Internet and smartphones are playing increasingly important roles in connecting people of all ages to news, information and services, older adults face challenges when they are using smartphones. There are barriers to older adults' use of mobile phones, including the lack of computer literacy, economic barriers, and privacy concerns. The term older adult has been defined in a variety of ways in different articles, which ranges from over 40 to over 75 . The distinction of "older" depends upon the specific context under consideration. We defined older adult as people over the age of 65 in this study.

Although some previous studies (e.g., $[11,16])$ have been reported on various benefits of using smartphones, little is known about the values of using smartphones from the perspectives of ageing population in China. Most previous research tended to focus on the use and adoption of smartphones [13] [14], and application development on smartphones (e.g., [21]). One of the effective ways in gaining a better understanding of the use of smartphones by older adults is to identify the values of using smartphones by engaging older smartphones users. This research intends to bridge the research gap in the values of using smartphones among older adults in China.

The objective of this study is to explore the values of using smartphones for older adults in China. The proposed research question is: what are the values of using smartphones for old adults. To address this, we employed the value-focused thinking (VFT) to identify the values of using smartphones with older adults in China. This is helpful to make the use of smartphones for older adults with maximized values.

The rest of the paper is organized as follows. We present the literature review in Section 2. Section 3 illustrates the research method. Section 4 describes the application of the methodology and results of this study. We discuss the findings of the study in Section 5. Section 6 concludes this research and points out some future research directions.

\section{$2 \quad$ Literature Review}

The literature related to this research is discussed in this section.

\subsection{Aging Society in China}

Due to the effects of one child policy in China, China's population is growing old at a faster rate than almost all other countries. The percentage of Chinese above the retirement age (i.e., 60 years old) is expected to reach 39 percent of the population by 2050 . Various technologies are being designed to enhance older adults' quality of life [4]. Among the various kinds of new technologies, the smartphone is the one of most commonly used products by older adults in their daily lives. Smartphones can be a powerful tool to tackle some challenges of older adults [1]. Smartphones are able to provide personalized health care and social services for older adults. However, the use of new technologies is not straightforward for older adults. For instance, it was found that anxiety was associated with using smartphones [6]. 


\subsection{Research on the Use of Smartphones}

Research work has been carried out by researchers in studying various aspects related to the use and adoption of smartphones [10]. In [3], Chen et al. combined TAM [5] and innovation diffusion theory (IDT) [25] to study and explain the adoption of smartphones in logistics. Self-efficacy was a strong predictor of behavioral intention through attitude. Based on a study on the performance of mobile applications, Huang et al. [15] indicated that smartphones could become a suitable substitute of traditional computers. But, the performance of the applications on smartphones is poorly understood.

Although significant effort has been done to explore the use and adoption of smartphones, there are not many studies on the values of using smartphones for older adults. The samples used in previous research are relatively young. In [26], Sheng et al, examined the values of the use of mobile technology in a leading publishing company by interviewing 12 sales representatives and district managers from the publishing company. Concerning the research on the use of new technologies by older adults, most previous research [29] tends to focus on the use and adoption of computers and Internet by older adults. Lee et al. [19] examined users' constraints of using computers at various age stages.

An examination of the current literature reveals that few studies have addressed the use and adoption of smartphones by older adults. Pheeraphuttharangkoon et al. [24] investigated the use and adoption of smartphones with older adults in the UK. However, the sample size with people over 50 years old was quite small in their study. In [13], the authors explored the adoption of smartphones with older adults in China and found that social influence, observability, compatibility, performance expectancy and perceived enjoyment, were important determinants for the use and adoption of smartphones with older adults in China.

Despite the increasing attention on the adotpion of smartphones with older adults, there is few studies focusing on the values of using smartphones with older adults. Therefore, to bridge the research gap, this study aims to investigate the values of using smartphones from the perspectives of older adults in China.

\section{Research Methodology}

The value focused thinking approach is a decision technique and defines a method which can help identify values and structure the identified values systematically[18]. These objectives which are of concern by users during the decision-making process make up the value portfolio. It offers the preconditions of each decision from decisionmakers' perspectives[17]. VFT approach can reach a means-ends objective network of fundamental objectives and means objectives.

In this study, we aim to get insights of the essential activities that must occur to maximize the values of using smartphones from the perspectives of older adults in China. Therefore, it is believed that VFT is an appropriate approach to address the research question. The VFT approach has been applied to the research in information systems, such as creativity in understanding users' privacy and security concerns with 
SNS [2], understanding the values of MOOCs in education from students' perspectives [12], the values of live game streaming [30], the values of blockchain based games [20], and strategic implications of mobile technology [26].

The VFT approach is chosen to answer the proposed research question 'what are the values of using smartphones from the perspectives of older adults in China?' and to assist in identifying value objectives.

The application of the VFT methodology in exploring older adults' perspectives on the value of using smartphones can result in a value map which helps us understand their user behavior and promote the digitalization among them. The VFT approach is designed to identify what is important and how this can be achieved as it focuses on what the decision-maker cares about [17,26].

In this study, we employ VFT approach as follows (see Figure 1):

-Step 1: Identify older adults. According to the defined age for older adults in Section 1 , we choose people more than 65 years old as our interviewees and gather information about the value estimated by them to help us gain an insight of the use of smartphones among them.

-Step 2: Develop a list of the initial value objectives and convert them into a common form. Several techniques such as wish lists, problems, shortcomings, and alternatives can help conclude the possible objectives from the insights and make them easier to comprehend.

-Step 3: Identify the objectives and distinguish the fundamental objectives from means objectives. Fundamental objectives are the ends that decision makers valued in a specified context, while means objectives are methods to reach the ends. In the process of distinguish means objectives from fundamental objectives and build their relationships, Keeney suggested using the question "why is that important" [18]. For each value objectives, the question will result into two types of possible responses. One is that this objective is one of the essential reasons for interest in the situation, and it is the fundamental for decision making. That is called fundamental objective. Another response is that the objective is important because of its implications for other objectives, which is called means objectives [28].

-Step 4: Build the means-end objective network on the basis of the third step. The network provides a model describing the specified relationships between fundamental objectives and means objectives. According to this, analysts could find out how fundamental objectives can be achieved via means objectives. And the relationships presented in the network can help analysts better understand the complex value system of decision makers.

\begin{tabular}{|c|c|c|c|}
\hline $\begin{array}{c}\text { Step 1: } \\
\text { Identify } \\
\text { older adults }\end{array}$ & $\begin{array}{c}\text { Step 2: De- } \\
\text { fine initial } \\
\text { value objec- } \\
\text { tives }\end{array}$ & $\begin{array}{l}\text { Step 3: Identify } \\
\text { fundamental } \\
\text { and means ob- } \\
\text { jectives }\end{array}$ & $\begin{array}{c}\text { Step 4: Build } \\
\text { the means-end } \\
\text { objective net- } \\
\text { work }\end{array}$ \\
\hline
\end{tabular}

Figure 1. Steps of VFT Approach 


\section{$4 \quad$ Application of the Methodology}

\subsection{Data Collection}

The data were collected from face to face interviews conducted from $15^{\text {th }}$ January 2019 to $31^{\text {st }}$ January 2019 in two cities in two different provinces in China. We sent interview invitations to twenty older adults in China who had some experience in using smartphones during the first week of January 2019. Eleven of them agreed to participate in the research and the face to face interviews were recorded. The VFT approach was applied to discover the values of using smartphones from the perspectives of older adults in China.

All participants were more than 65 years old who had some experience in using smartphones. Thus, it is believed that the interviewees were aware of the use of smartphones and would have some thoughts to be shared regarding the values of using smartphones.

\subsection{Identifying the Value Objectives}

By following the VFT approach, we interviewed the participants with the probing questions below:

"What are the benefits of using smartphones, and why is that important?"

"What difficulties have you experienced in using smartphones?"

"What kind of supports have you received to use smartphones?"

"Do you have some expectations on using smartphones?"

By asking these questions, we primarily discovered the objectives of older adults' usage of smartphones and formed an initial list of objectives. Then, we asked participants "why is that important" to get a further understanding of the initial list of objectives. The interviewees needed to consider and review the decision of using smartphones and the whole process. Until they have arrived at the most important value, fundamental objectives could be seized and distinguish fundamental objectives from means objectives. Objectives can be classified into means objectives and fundamental objectives. Means objectives contributed to the achievement of fundamental objectives. Finally, a means-end objective network was draw to present the relationships between these objectives.

\subsection{The Fundamental Objectives and Means Objectives}

Two researchers firstly conducted coding of four interviews, and identified fundamental objectives and means objectives from the interview material independently. Then the coding results had been compared, with $90 \%$ of the coding in the same. Some ambiguities caused by oral and written expression had been discussed. After an agreement was reached, one researcher coded the remaining data from the interviews. Once all coding has been completed, three researchers reviewed all the coding results to merge duplicate values and remove the extra values. The results of the identification of value objectives were showed in Table 1. 
Table 1. The fundamental objectives

\begin{tabular}{|c|c|}
\hline Fundamental objectives & Evidences from the interviews \\
\hline Maximize well-being & $\begin{array}{l}\text { I enjoy the interactions with my relatives and friends using } \\
\text { various applications on smartphones. } \\
\text { I achieve a sense of fulfillment due to the use of smartphones. }\end{array}$ \\
\hline Maximize life efficiency & $\begin{array}{l}\text { I can check the time and weather on the phone which help me } \\
\text { better plan my daily activities. } \\
\text { I can pay bills and shop online with the Ali-pay and Wechat } \\
\text { which are convenient and can save my time. }\end{array}$ \\
\hline Maximize safety & $\begin{array}{l}\text { When I hang out, I can use my smartphone to tell my children } \\
\text { where I am and what I am doing to make sure that I am safe. } \\
\text { By checking the weather by using smartphones, I can avoid } \\
\text { going out in a bad weather condition. }\end{array}$ \\
\hline Maximize digital inclusion & $\begin{array}{l}\text { I want to integrate into the digital society by using } \\
\text { smartphones. } \\
\text { My children and my friends help me using smartphones. }\end{array}$ \\
\hline
\end{tabular}

Maximize well-being. Improving the well-being of older adults is the ultimate goal of the whole society. It involves the effort from the society, governments and individuals. Using smartphones enables older adults to engage in more activities, gain more practical information, and receive more cares from others. Older adults living apart from their children would cause many potential social problems. For instance, older adults may suffer intense loneliness. Using smartphones would help them diminish their loneliness and enjoy their lives in the society.

Maximize life efficiency. Using smartphones among older adults is becoming more and more common in China although there are still many problems to be addressed. It offers many useful features for older adults. For example, they can check the time and weather on the phone, which help them better plan their daily activities. What's more, as the mobile payment getting more and more popular in China, old adults are encouraged to use mobile payments when possible. And some older adults also do mobile shopping with the assistance from others. The use of smartphones increases their life efficiency.

Maximize safety. Health problem is one of the most important issues among older adults living independently. Their children would like to pay close attention to their health conditions and daily routines. Older adults can reach their children easily by using application on smartphones. For example, older adults can inform their children via sending instant voice messages by using smartphones. The location information of older adults can be tracked by using location-based applications on smartphones.

Maximize digital inclusion. The use of smartphones can be seen as a mean to help older adults integrate into the digital society. Along with the development and advancement of digital technologies, there are many concerns with the use and adoption of smartphones among older adults. The data collected from the interviews also indicated that the social influence from others gave impetus to the efforts toward the digital inclusion.

The means objectives are the ways to achieve the fundamental objectives. From the initial means objectives, we did another coding to assure the result is detailed and 
without any redundancy. Table 2 summarizes 12 means objectives and evidences from the interviews.

Table 2. The means objectives

\begin{tabular}{|c|c|}
\hline Means objectives & Evidences from the interviews \\
\hline Customize apps for older adults & $\begin{array}{l}\text { - There are many features I never use on my smartphone. } \\
\text { I wish there would be more voice-enabled mobile applica- } \\
\text { tions. }\end{array}$ \\
\hline Assure user-friendly interface & $\begin{array}{l}\text { When using a smartphone, text on the screen are too small } \\
\text { and I always find it difficult to see the text. } \\
\text { The ringtone volume on my smartphone is too low so that } \\
\text { sometimes I would miss the phone call. }\end{array}$ \\
\hline Reduce language barriers & $\begin{array}{l}\text { I grew up during the period where education was hardly of- } \\
\text { fered in China } \\
\text { Since I am unable to read the text message, I prefer to receive } \\
\text { voice messages via applications on my smartphone. }\end{array}$ \\
\hline Simplify the operation & $\begin{array}{l}\text { I cannot always remember how to operate the apps on my } \\
\text { smartphone in an appropriate manner. } \\
\text { The operation of smartphone is too complex for older adults } \\
\text { like me, for example, to run an application, I have to touch } \\
\text { screen several times. }\end{array}$ \\
\hline Receive help from others & $\begin{array}{l}\text { My grandchildren helped me use my smartphone. } \\
\text { When I have questions on the use of smartphones, my chil- } \\
\text { dren can give me assistance. }\end{array}$ \\
\hline Meet needs from older adults & $\begin{array}{l}\text { - Nowadays, it is difficult to find interesting TV programs for } \\
\text { older adults on TV. However, I can find my favorite operas in } \\
\text { different video applications on my smartphones. } \\
\text { There are many applications on my smartphone that I never } \\
\text { use while sometimes I cannot find what I need on my } \\
\text { smartphone. }\end{array}$ \\
\hline Enable easier to use & $\begin{array}{l}\text { Touching screen is not easy to use. I prefer to have a } \\
\text { smartphone with a physical keyboard. } \\
\text { Straightforward operations on a smartphone would motivate } \\
\text { me to have a continuous intention to use the smartphone. }\end{array}$ \\
\hline Increase communication & $\begin{array}{l}\text { - Using smartphones enables me to communicate with my rela- } \\
\text { tives and friends more frequently. } \\
\text { I can talk with my relatives and friends quite often by using } \\
\text { application on my smartphone. }\end{array}$ \\
\hline $\begin{array}{l}\text { Enrich activities for older } \\
\text { adults }\end{array}$ & $\begin{array}{l}\text { My friends often organize activities by posting group mes- } \\
\text { sages on Wechat. } \\
\text { I often listen to music and watch videos in various applica- } \\
\text { tions on my smartphone. }\end{array}$ \\
\hline $\begin{array}{l}\text { Get information from multiple } \\
\text { sources }\end{array}$ & $\begin{array}{l}\text { I can read news and feeds by using applications on my } \\
\text { smartphone. } \\
\text { I can be informed with important and useful information via } \\
\text { various apps on my smartphone. }\end{array}$ \\
\hline Minimize loneliness & $\begin{array}{l}\text { I can share my moments and daily activities easily with my } \\
\text { relatives and friends via Wechat on my smartphone. Thus, I } \\
\text { feel being socially connected with them. } \\
\text { When I am alone or boring, I often check posting from my } \\
\text { relatives and friends on Wechat. }\end{array}$ \\
\hline Maximize care & $\begin{array}{l}\text { My children often message me via apps to show their care. } \\
\text { Although my children don't live in the same city with me, } \\
\text { they often talk to me by making video calls via their } \\
\text { smartphones. }\end{array}$ \\
\hline
\end{tabular}




\subsection{The Means-Ends Objective Network}

Based on the identified fundamental objectives and means objectives structured in this study and the relationship between the two types of objectives, a means-ends objective network was developed (see Figure 2) [27]. The developed network indicated that using smartphones was able to provide many values for older adults in China although there were some barriers for older adults to use smartphones in an efficient manner. Using smartphones provides a new opportunity for older adults to be connected in the digital society. It helps them strengthen the tie with their relatives and friends. Moreover, it also helps them engage in different online communities. There are many hobby groups for older adults on Wechat, such as dancing groups and hiking groups. They can use Wechat on their smartphones to organize different activities. In addition, they are able to keep updated with or subscribe the latest news by using different apps on their smartphones. Besides this, some older adults have enthusiasm to learn skills with the use of smartphones (e.g., using mobile shopping and mobile payment) which enable them to keep connected with the new technologies.

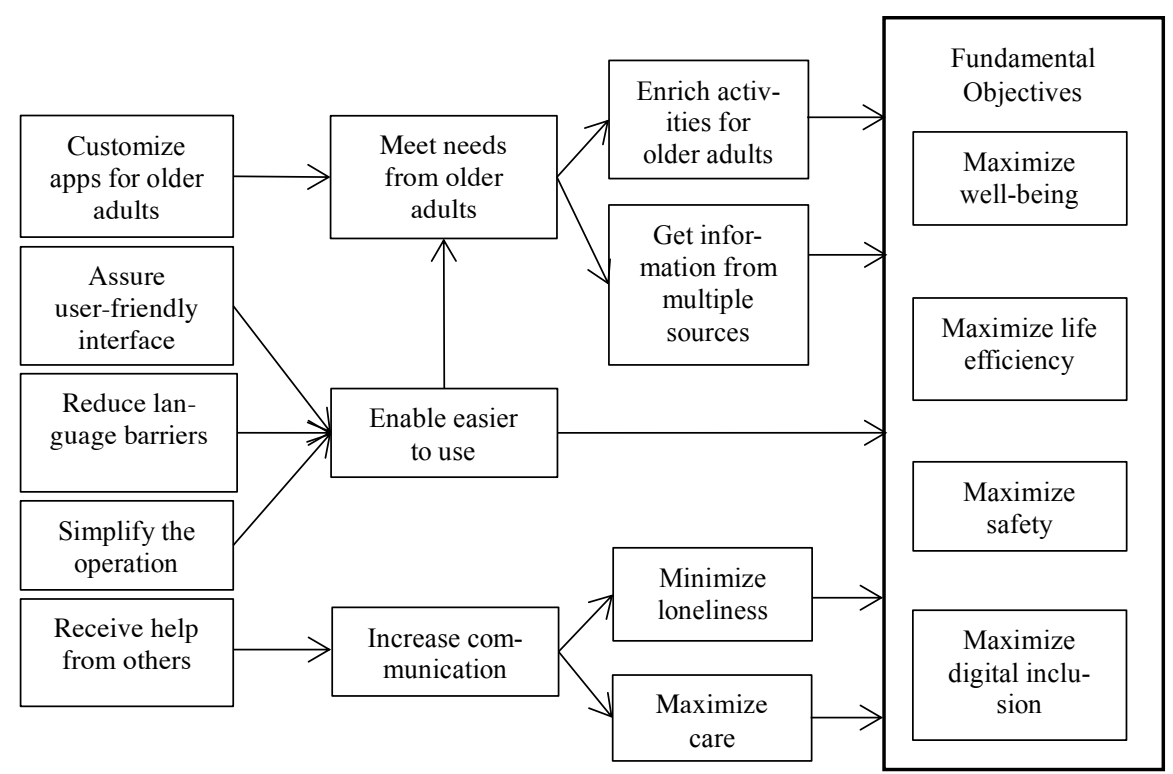

Figure 2. the means-ends objective network

\section{Discussion on the Findings}

This study used a qualitative research approach to understand the values of using smartphones from older adults' perspectives in China (e.g., what do older adults expect with the use of smartphones), and developed a means-ends objective network that depicts these values and their relationships. This study contributed to the literature on the 
use of smartphones. It contributed to the existing literature on using VFT approach to explore the values of using smartphones for older adults in China.

Some features of smartphones need to be further enhanced. Older adults did not use many apps on their smartphones in a right manner although many apps were designed to make their lives' easier, safer and more efficient. It helps them enrich their retirement life and improve their well-beings. For instance, there were many apps on the smartphones that were not used by older adults, such as healthcare applications and fitness applications, which aimed to help older adults manage their health conditions. But these values were nearly never indicated in the interviews with older adults.

Along with the development of new digital technologies, some older adults were under the social pressure to keep up to date with the digitalization and increase their digital inclusion. Various assistances from people around older adults have an important role in promoting the use of smartphones among older adults. This is in line with the findings in [24]. It can help them reduce social pressure and eliminate the difficulties with the use of smartphones.

The findings from this research also offered some practical implications. It is important to get older adults involved in the development of applications on smartphones. The results indicated that older adults were interested in using smartphones. They wanted the developed applications on smartphones easier to use. Thus, it is believed that they want to express their opinions on the developed applications on smartphones before using them. Furthermore, the governmental sectors need to work on more initiatives on helping older adults using smartphones. Most respondents in this study wanted to be included in the digital society. However, some of them were not good at using smartphones. If the governmental sectors can organize some training sessions for using smartphones in older adults' communities, it would facilitate the learning process of using smartphones for older adults. As a result, it would be more likely to maximize the values of using smartphones for older adults. The social security service sectors can invest additional resources in developing customized information-oriented applications for older adults on smartphones. Then, it would be easier for older adults to get access relative information on their smartphones.

\section{Conclusion and Future Research}

This study investigated the values of using smartphones in peoples' daily lives from the perspectives of older adults in China by using VFT approach. Based on the data collected from the interviews, we developed a means-ends objective network describing the values of using smartphones for older adults in China. The developed network included twelve means objectives and four fundamental objectives. The results indicated that using smartphones for older adults in China entailed fundamental objectives such as increased well-being, increased digital inclusion, increased awareness of safety, and increased life efficiency. The derived fundamental objectives in this study can serve as factors in assessing the success of using smartphones in older adults' daily lives in China. 
We are also aware of some limitations of this study. The sample size of this study was quite small. Therefore, the generalizability of the results to other users remains to be determined. Secondly, the participants of this study were only from two provinces in China. Although they can represent older adult users of smartphones to some extent, they may not reflect the total population of older adults in China. Thirdly, the process of identifying values might be subjective. And there might be a potential age-gap between the interviewers and the interviewees. Last but not least, there are other possible research methodologies could be used to examine the values of using smartphones for older adults.

We plan to refine the means-ends objective network by collecting additional data from older adults in China. Furthermore, we also plan to expand the research by identifying the values of using smartphones from older adults' perspectives in some other countries.

\section{References}

1. Barnard, Y., Bradley, M.D., Hodgson, F., et al.: Learning to use new technologies by older adults: Perceived difficulties, experimentation behaviour and usability. Computers in Human Behavior. 29 (4), 1715-1724 (2013)

2. Barrett-Maitland, N., Barclay, C. and Osei-Bryson, K.-M.: Security in Social Networking Services: A Value-Focused Thinking Exploration in Understanding Users' Privacy and Security Concerns. Information Technology for Development. 22 (3), 464486 (2016)

3. Chen, J.V., Yen, D.C. and Chen, K.: The acceptance and diffusion of the innovative smart phone use: A case study of a delivery service company in logistics. Information \& Management. 46 (4), 241-248 (2009)

4. Chen, K. and Chan, A.H.: The ageing population of China and a review of gerontechnology. Gerontechnology. 10 (2), 63-71 (2011)

5. Davis, F.D.: Perceived usefulness, perceived ease of use and user acceptance of information technology. MIS Quarterly. 13 (3), 319-340 (1989)

6. Elhai, J.D., Levine, J.C., Dvorak, R.D., et al.: Fear of missing out, need for touch, anxiety and depression are related to problematic smartphone use. Computers in Human Behavior. 63, 509-516 (2016)

7. Gao, S. and Krogstie, J.: Understanding Business Models of Mobile Ecosystems in China: A Case Study. In: the proceedings of the 7th International Conference on Management of computational and collective IntElligence in Digital EcoSystems (MEDES'15). ACM (2015)

8. Gao, S., Krogstie, J., Chen, Z., et al.: Lifestyles and Mobile Services Adoption in China. International Journal of E-Business Research (IJEBR). 10 (3), 36-53 (2014)

9. Gao, S., Krogstie, J. and Siau, K.: Adoption of mobile information services: An empirical study. Mobile Information Systems. 10 (2), 147-171 (2014)

10. Gao, S., Krogstie, J. and Siau, K.: Developing an Instrument to Measure the Adoption of Mobile Services. Mobile Information Systems. 7 (1), 45-67 (2011) 
11. Gao, S., Krogstie, J., Thingstad, T., et al.: A mobile service using anonymous locationbased data: finding reading rooms. International Journal of Information and Learning Technology. 32 (1), 32-44 (2015)

12. Gao, S., Li, Y. and Guo, H.: Understanding the Value of MOOCs from the Perspectives of Students: A Value-Focused Thinking Approach. 129-140. Springer International Publishing (2018)

13. Gao, S., Yang, Y. and Krogstie, J.: The Adoption of Smartphones Among Older Adults in China In: Liu, K., Nakata, K., Li, W., et al. (eds.) Information and Knowledge Management in Complex Systems. 449. Springer Berlin Heidelberg (2015)

14. Hoehle, H. and Venkatesh, V.: Mobile application usability: Conceptualization and instrument development. Mis Quarterly. 39 (2) (2015)

15. Huang, J., Xu, Q., Tiwana, B., et al.: Anatomizing application performance differences on smartphones. In: Proceedings of the 8th international conference on Mobile systems, applications, and services, 165-178. ACM (2010)

16. Hubert, M., Blut, M., Brock, C., et al.: Acceptance of smartphone-based mobile shopping: Mobile benefits, customer characteristics, perceived risks, and the impact of application context. Psychology \& Marketing. 34 (2), 175-194 (2017)

17. Keeney, R.L.: Creativity in decision making with value-focused thinking. Sloan Management Review. 35 (4), 33 (1994)

18. Keeney, R.L.: Value focused thinking - a path to creative decisionmaking. Harvard University Press, Cambridge, US (1992)

19. Lee, B., Chen, Y. and Hewitt, L.: Age differences in constraints encountered by seniors in their use of computers and the internet. Computers in Human Behavior. 27 (3), 12311237 (2011)

20. Li, Y. and Gao, S.: Understanding the Values of Blockchain Based Games from Users' Perspectives: A Value-focused Thinking Approach. In: 18th Wuhan International Conference on E-Business (WHICEB 2019), Wuhan, China, May 24-26, 2019. Association for Information Systems (2019)

21. Mata, P., Chamney, A., Viner, G., et al.: A development framework for mobile healthcare monitoring apps. Personal and Ubiquitous Computing. 19 (3-4), 623-633 (2015)

22. Morris, M.E. and Aguilera, A.: Mobile, social, and wearable computing and the evolution of psychological practice. Professional Psychology: Research and Practice. 43 (6), 622 (2012)

23. Peacock, S.E. and Künemund, H.: Senior citizens and Internet technology. European journal of ageing. 4 (4), 191-200 (2007)

24. Pheeraphuttharangkoon, S., Choudrie, J., Zamani, E., et al.: Investigating the adoption and use of smartphones in the UK: a silver-surfers perspective. In: the 22nd European Conference on Information Systems (ECIS2014) (2014)

25. Rogers, E.M.: Diffusion of Innovations. 1995. Woerkom van C, Kuiper D, Bos E. Communicatie en innovatie, een inleiding. Alphen aan den Rijn: Samsom, 2 (1999)

26. Sheng, H., Nah, F. and Siau, K.: Strategic Implications of Mobile Technology: A Case Study Using Value-Focused Thinking. Journal of Strategic Information Systems. 14 (3), 269-290 (2005) 
27. Sheng, H., Nah, F.F.H. and Siau, K.: Value-focused thinking and its application in MIS research. Journal of Database Management. 18 (3), I-V (2007)

28. Sheng, H., Siau, K. and Nah, F.F.-H.: Understanding the values of mobile technology in education: a value-focused thinking approach. ACM SIGMIS Database. 41 (2), 2544 (2010)

29. Wagner, N., Hassanein, K. and Head, M.: Computer use by older adults: A multidisciplinary review. Computers in Human Behavior. 26 (5), 870-882 (2010)

30. Yang, X. and Gao, S.: Understanding the Values of Live Game Streaming: a ValueFocused Thinking Approach. In: 16th Wuhan International Conference on E-Business (WHICEB 2017), Wuhan, China, May 26-27, 2017, 394-401. Association for Information Systems (2017) 